\title{
Aprendre geologia urbana
}

\author{
Josep Girabal i Guitart \\ Camp d'Aprenentatge del Bages, Manresa \\ jgirabal@xtec.cat
}

Es presenten diversos itineraris de geologia urbana per la comarca del Bages adreçats a alumnes d'ESO o final de Primària. L'article enllaça amb documents que guien l'alumnat en les diferents activitats proposades.

Paraules clau: geologia urbana, itinerari, roques, observació, cristalls

Entenem per geologia urbana l'estudi de les roques emprades en la construcció dels edificis, carrers i monuments, però també s'usa aquest terme per referir-se a l'estudi del substrat geològic natural de les ciutats, que no és el tema d'aquest treball, encara que si és visible el tindrem en compte.

Al Camp d'Aprenentatge del Bages ja fa uns anys que vam dissenyar un itinerari de geologia urbana pel centre de Manresa. Actualment, gràcies a haver obtingut una Llicència d'estudis B2 per al projecte "Aprenent Geologia al Bages", comptem ja amb un bon nombre d'itineraris a diverses poblacions de la comarca i, el que és més important, amb una metodologia que hem anat afinant amb la pràctica.

Des de bon principi hem comptat amb la col-laboració del Museu de Geologia Valentí Masachs.

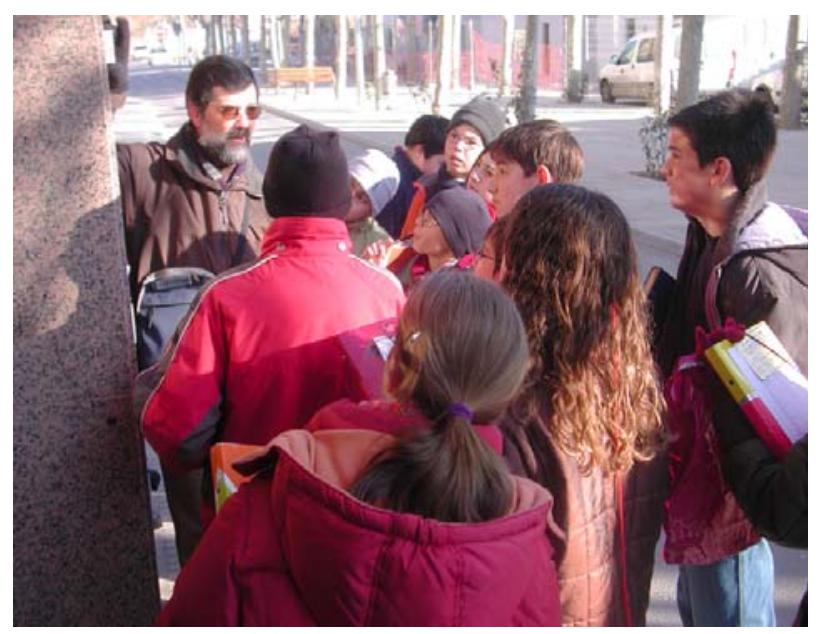

\section{Per què fem geologia urbana?}

\section{Per a molta gent, és la geologia més a l'abast}

La vida de gran part de la població transcorre bàsicament en un medi urbanitzat, i per tant els materials geològics que es troba en la seva vida quotidiana són els de les façanes, enllosats, escales, cuines o banys. Per què no els estudiem?

\section{Un museu sempre obert}

Actualment als nostres carrers podem veure una gran varietat de roques que abans només hauríem trobat en un museu. La globalització també ha arribat a la pedra de construcció, de manera que al costat de les roques autòctones dels edificis antics en tenim de procedents d'altres països i continents.

\section{Cal treure l'escola al carrer}

Creiem que sempre que es pugui cal aprendre directament de la realitat, especialment quan l'objecte d'estudi el tenim tan a l'abast com el que tractem.

Tot i que no és gaire habitual veure professors $\mathrm{i}$ alumnes treballant al carrer hauríem de perdre la vergonya d'ensenyar i aprendre a la vista de tothom, fins i tot per interès social, ja que convertir el carrer en un espai educatiu honra tota la comunitat.

\section{Estimular l'esperit d'observació}

Veiem moltes coses, però en mirem poques, potser és per la gran quantitat d'estímuls visuals que rebem actualment. Un itinerari de geologia urbana estimula l'esperit d'observació. I la lliçó de geologia no s'acaba al final de la caminada, sinó que es repassa cada dia quan es fa el recorregut 
habitual. L'alumne relacionarà les roques observades amb les que té a la seva escala, al bany o a la cuina. Ens ha passat a tots: tenim la geologia a casa i la veiem, però no la mirem.

\section{Civisme}

Un itinerari ha de contemplar també els casos de degradació (natural i humana) de la pedra: brutícia, papers enganxats, pixarades de gossos, pintades... La degradació natural ens permet conèixer les propietats de la pedra, mentre que el mal causat per l'acció humana en el nostre objecte d'estudi sol crear una actitud crítica envers les conductes incíviques.

\section{Fem-ho fàcil}

Com passa en tots els aprenentatges, el grau d'aprofundiment s'ha d'adaptar a la capacitat dels alumnes. Les roques ja s'estudien a Cicle Superior de Primària, i l'activitat, tal com la plantegem, es pot fer amb alumnes d'aquests nivells i, evidentment, amb els de Secundària.

Cal reconèixer que la classificació de les roques, especialment les magmàtiques, no és fàcil: la presència d'un determinat mineral o la proporció entre els diversos components diferencien roques que a ull nu i sense ser-ne expert no distingim. Com que no volem atabalar l'alumnat sinó despertar el seu interès i la seva capacitat d'observació, utilitzem una classificació ben simple de les roques, tal com es pot comprovar en els rètols informatius: unes poques característiques bàsiques que ens permetin una identificació elemental però correcta.

Una complicació afegida són els noms comercials de la pedra, dels quals prescindim ja que no solen coincidir amb la nomenclatura geològica i poden crear confusions.

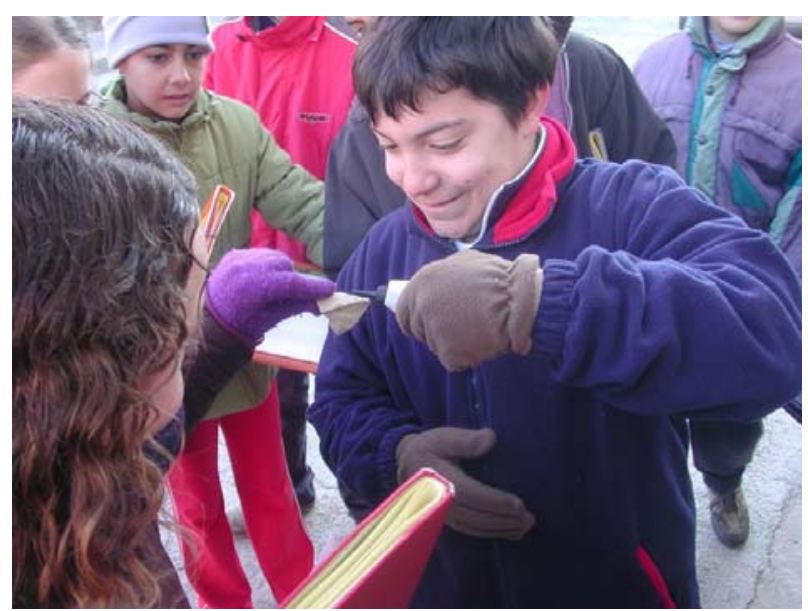

\section{GUIÓ DE L'ACTIVITAT QUE PROPOSEM}

Creiem que la metodologia i el material necessari per fer aquesta activitat és senzilla i a l'abast de tothom. Per això animem a mestres i professors interessats a fer aquesta activitat d'aprenentatge fora de l'aula.

A continuació teniu el guió que seguim al Camp d'Aprenentatge del Bages i en hipertext el material per imprimir.

\section{Coneixements previs recomanables}

Anirà bé que els alumnes coneguin de forma elemental la gènesi i característiques generals de les tres classes de roques: magmàtiques, sedimentàries i metamòrfiques. Si es vol aprofundir una mica sobre el tema es pot tractar del cicle geològic de les roques.

\section{Sessió prèvia opcional: taller de formació de cristalls}

Per ajudar a entendre la formació de les roques magmàtiques i dels cristalls proposem algunes activitats pràctiques per fer uns dies abans de l'itinerari. Són senzilles i es poden fer amb la dotació ordinària d'un centre educatiu i uns pocs productes químics.

Les més conegudes són les que permeten obtenir cristalls a partir de sals dissoltes. Són pràctiques fàcils i econòmiques per a les quals hem elaborat uns senzills guions de treball:

- Obtenció de cristalls de sals solubles per evaporació

- Formació de cristalls grans a partir d'una dissolució

També es poden formar cristalls en una reacció química: Us proposem una experiència sorprenent:

- Veure com creixen els cristalls en temps real, davant dels nostres ulls.

Malgrat la seva utilitat, el procés de formació de cristalls en aquestes pràctiques no és el mateix que porta a la formació de roques magmàtiques, que és el refredament i solidificació, com en el cas següent: 
- La cristal-lització del salol, una substància que fon i solidifica a $42{ }^{\circ} \mathrm{C}$ i sense perill de cap mena permet comparar els cristalls formats a diferents velocitats de refredament.

\section{Organització de la sortida}

Es comença donant les instruccions sobre comportament al carrer i desenvolupament del treball, remarcant la necessitat d'una actitud participativa, de manera que les observacions i exercicis siguin fets i resolts en comú, procurant que cap membre del grup en quedi desvinculat.

Anirà bé fer-ho amb no més de 12-13 alumnes per professor.

\section{Entrega de material}

\section{Individual}

- Full d'anotacions

- Una taula en la que hauran d'anar marcant el tipus de roca que troben a cada lloc. Podeu veure'n algun exemple: Pel centre de Manresa, per la rodalia del CEIP Bages, i a partir de les escoles d'Avinyó, Artés i Castellbell i el Vilar

\section{Per a cada grup}

Caldrà tenir preparat el següent material:

- Rètols de les tres classes de roques

- Rètols informatius de les roques

- Tall geològic del cicle de les roques

- Àcid clorhídric diluît per comprovar l'efervescència

- Una ampolla d'aigua per si cal netejar la pols de les pedres

- Paper de cuina per eixugar

- Càmera fotogràfica (almenys una per a cada grup)

- Mostres de mà de cada pedra (fragments petits de planxes de marbristes)

- Opcionals: nummulits, closca i pua d'eriçó de mar, quars, feldspat, mica, etc.

Tot això s'haurà de repartir, de manera que tothom tingui mostres i que tots participin en la prova de l'àcid, en la neteja de la pedra i en la manipulació de mostres.

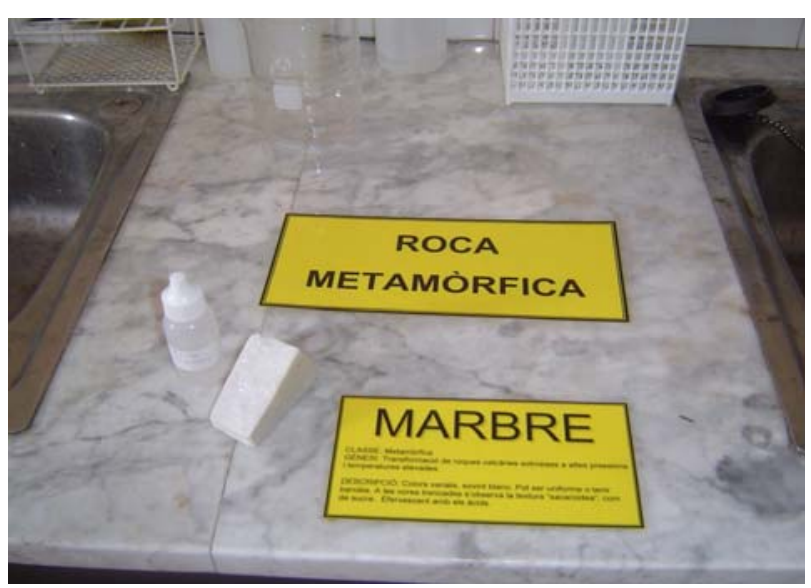

\section{Itinerari urbà}

S'anirà seguint el recorregut que marca la taula d'anotacions. A cada parada caldrà fer observar atentament la roca, anirà bé fer-la descriure oralment, comparar-la amb les vores trencades de les mostres de mà i identificar-la consultant els rètols informatius que se'ls ha repartit. La comprovació de l'efervescència amb l'àcid es farà sobre les mostres de mà, mai sobre els edificis.

El quars, feldespat, la mica, els fòssils i les closques d'animals marins ajudaran a entendre la constitució de les roques que els contenen: respectivament, el granit i les diverses calcàries fossilíferes.

Quan es doni el cas, cal fer observar els efectes de l'atmosfera, el desgast degut a l'ús, l'alteració per pixarades de gossos, la brutícia, les pintades... Tot plegat ajudarà a conèixer les propietats de cada pedra i a reflexionar sobre les conseqüències de l'incivisme.

Cada alumne haurà de complimentar l'espai corresponent al full de treball, i qui porti càmera fotogràfica anirà fent les fotos amb els rètols posats damunt de cada pedra estudiada.

\section{A l'acabar l'itinerari: muntar una exposició a l'aula}

Un cop acabat l'itinerari es muntarà una exposició de mostres de roques agrupades per classes (magmàtiques, metamòrfiques i sedimentàries), amb el rètol del seu nom i els minerals o fòssils relacionats amb cada una.

\section{Material necessari}

- Tot el que s'ha utilitzat a l'itinerari: Rètols, mostres, minerals, closques, tall geològic... 
- Mostres de les roques observades o altres de similars, en peces quadrades o rectangulars de mides entre 5 i $15 \mathrm{~cm}$ (retalls de taller de marbrista)

Aconsellem no desmuntar immediatament l'exposició resultant i aprofitar-la per fer-hi visites comentades amb altres grups, sent els mateixos alumnes que l'han muntada els qui l'expliquin als seus companys.

\section{Treballs posteriors}

Recomanem passar el video "De la pedrera a casa" sobre l'extracció i transformació de la pedra de construcció, comentar-lo i realitzar una fitxa de treball per reforçar o avaluar el que s'ha après en veure'l. Està disponible a la videoteca Edu3.cat i es va fer gràcies a la meva llicència d'estudis i a la col-laboració del Servei de Mitjans Audiovisuals del Departament d'Educació.

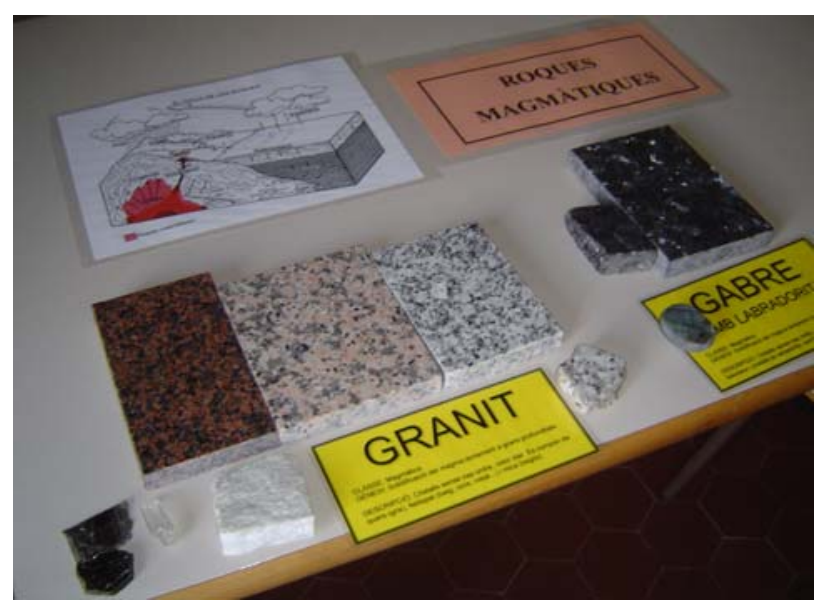

\section{Animeu-vos!}

No serà difícil muntar una activitat de geologia urbana com les que fem al CdA del Bages, Les roques utilitzades actualment a la construcció són les mateixes arreu, de manera el vostre futur itinerari es pot assemblar força a algun dels que plantegem, i les mostres de roques polides us les donarà qualsevol marbrista, ja que per a ell són material de rebuig.

A més, un itinerari de geologia urbana es fa a peu, sense despeses ni viatges, i altera molt poc l'organització del centre.

\section{Uns consells}

- Que no hi falti la pedra de construcció tradicional a la zona, que sol ser extreta de l'entorn proper. Ben segur que la veureu en edificis una mica antics.

- Incloure roques de les tres classes: magmàtiques, sedimentàries i metamòrfiques.

- Començar l'itinerari estudiant la pedra del propi centre educatiu, si n'hi ha.

- Prioritzar els carrers habituals que recorren els alumnes: els que convergeixen al centre, plaça, passeig o indret de reunió habituals, si són a prop.

- Abans d'estrenar l'activitat amb alumnes, anirà bé fer-la amb adults, si pot ser, companys de feina. Va bé com a assaig i segur que agradarà.

La realització d'aquest treball ha estat possible gràcies a una llicència retribuïda concedida pel Departament d'Educació i Universitats de la Generalitat de Catalunya (DOGC núm. 4699 de 17.8.2006). 